\title{
Rol de la paridad y HPV en el cáncer de cuello uterino
}

Role of parity and human papillomavirus in cervical cancer:the IARC multicentric case- control study. Muñoz N.,Francechi S, Bosetti C. The Lancet. Vol 359; 1093-2000

\section{Objetivo}

Evaluar el efecto de la paridad en la progresión de la infección por papiloma virus humano (HPV) a cáncer de cuello uterino.

Diseño

Estudio de casos y controles ${ }^{\star}$, multicéntrico. Se excluyeron mujeres con patologías asociadas a factores riesgo para cáncer de cuello. La positividad para HPV se evaluó mediante técnicas de detección de ADN. Lugar

Marruecos,Brasil,Perú, Paraguay, Colombia,Tailandia ,Filipinas y España. Pacientes

Se incluyeron 1989 mujeres con carcinoma cervical y 1916 controles. El análisis se restringió solo a mujeres HPV (+), quedando compuesta la muestra por 1465 pacientes con carcinoma invasivo escamoso, 211 con carcinoma in situ, 124 con adenocarcinoma o adenoescamoso, y 255 controles.

Evaluación de los factores de riesgo

Encuestadores entrenados efectuaron entrevistas personales evaluando información acerca de: factores sociodemográficos ,comportamiento sexual y reproductivo, medicación anticonceptiva, taba$\mathrm{co}$, historia de PAP, higiene e historia de ETS. La información evaluada para cada embarazo fue: edad, fecha de finalización, resultado, tipo de parto.

\section{Medición de resultados principales}

Se midió el riesgo de cáncer según paridad expresado en odds ratio*, ajustado mediante un análisis multivariable*.

Resultados principales

Luego del ajuste, se encontró una asociación directa entre el número de embarazos a término y el carcinoma escamoso. El OR para 7 o mas embarazos a término fue de 3.8 (IC95 \% 2.7 - 5.5), comparado

con nulíparas, y de 2.3 (IC 95\% 1.6 - 3.2), si se las compara con mujeres que tuvieron 102 embarazos a término. No hubo asociación entre riesgo de adenocarcinoma o carcinoma adenosecamoso y el número de embarazos a término.(Tabla 1) La edad temprana al primer hijo y el ușo de anticonceptivos orales por mas de 5 años también se asociaron a un incremento en el riesgo.

\section{Tabla 1: Riesgos según paridad}

\begin{tabular}{|c|c|c|c|c|}
\hline & $\begin{array}{l}\text { Riesgo de } \\
\text { mujeres HP }\end{array}$ & $\begin{array}{l}\text { eseamoso en } \\
\text { según paridad }\end{array}$ & $\begin{array}{r}\mathrm{R} \\
\mathrm{HPV}\end{array}$ & $\begin{array}{l}\text { de positividad para } \\
\text { n paridad en controles }\end{array}$ \\
\hline & $\begin{array}{l}\text { casos/ } \\
\text { controles }\end{array}$ & $\begin{array}{l}\text { Oddds ratio } \\
\text { (IC } 95 \%) t\end{array}$ & HPV(+)/ Total & $\begin{array}{l}\text { Odis ratio } \\
\text { (IC } 95 \%) \neq\end{array}$ \\
\hline Nulíparas & $57 / 24$ & $1.00(0.55-1.81)$ & $24 / 132$ & $2.09(1.23-3.58)$ \\
\hline $1-2$ & $279 / 59$ & $1.81(1.31-2.52)$ & $59 / 553$ & $1.00(0.74-1.36)$ \\
\hline $3-4$ & $450 / 70$ & $2.55(1.95-3.34)$ & $70 / 562$ & $1.12(0.87-1.44)$ \\
\hline $5-6$ & $353 / 48$ & $2.83(2.02-3.96)$ & $48 / 314$ & $1.22(0.87-1.71)$ \\
\hline$>=7$ & $534 / 52$ & $3.82(2.66-5.48)$ & $52 / 344$ & $1.16(0.80-1.67)$ \\
\hline$p$ (test par & a tendencia) & 0.0002 & & 0.56 \\
\hline
\end{tabular}

† Ajustado por centro de estudio, edad, educación, tabaco, edad de inicio de relaciones sexuales, número de parejas, uso anticonceptivos orales, e historia de PAP

‡ Ajustado por centro del estudio, edad, educación, tabaco, edad al inicio de las relaciones sexuales, uso de anticonceptivos orales, historia de PAP

\section{Conclusión}

El incremento de la paridad aumenta el riesgo de cáncer escamoso de cuello, entre mujeres HPV positivas. La disminución de la paridad en la población, explicaría parcialmente, la reducción de cáncer cervical observada en la mayoría de los países.

Fuente de Financiamiento: no referida

\section{Comentario}

La infección por HPV ha sido reconocida como causa necesaria pero no suficiente para el desarrollo de un carcinoma de cuello. La detección del virus en vagina es frecuente y su presencia habitualmente transitoria. Las causas que determinan que en ciertos individuos la infección persista y progrese a carcinoma se desconocen. Estudios observacionales han identificado múltiples asociaciones de riesgo, pero aún es poco claro si su real impacto no esta sobrestimado por potenciales factores de riesgo no controlados ${ }^{1-6}$. El estudio de Muñoz y col. muestra que el incremento de la paridad se asocia en forma independiente al riesgo de desarrollar un carcinoma en mujeres HPV positivas. Considerando el diseño del estudio, la restricción a mujeres HPV (+) permite controlar el efecto confundidor* de esta variable. De hecho en casos y controles HPV negativos, esta asociación no puede demostrarse. Sin embargo, desde un punto de vista biológico, debe tenerse en cuenta la naturaleza transitoria de la infección. Así es que algunos estudios consideran infección con 2 determinaciones positivas separadas por un lapso de tiempo; una sola determinación positiva puede indicar infección reciente y una negativa no excluye contacto o positividad previa. ${ }^{2}$

Llama la atención que el riesgo de tener HPV sea mayor en las nuliparas, lo que podría indicar una diferente conducta sexual. En poblaciones desprotegidas, el embarazo es quizás uno de los pocos contactos de la mujer con el sistema de salud y la posibilidad de acceder a una citología. En este estudio solo el $1.2 \%$ de los casos y el $9 \%$ de los controles eran nulíparas; mas aún, el 32\% de los casos tenían 7 o mas embarazos.

La población control fue mayormente de base hospitalaria, sin es-

pecificarse en el estudio criterios de exclusión. Es poco claro entonces, si esta población control es similar al resto de la población que no consulta, y por lo tanto los reales efectos de la paridad no estén sobrestimados. En la República Argentina murieron en el año 2000 , aproximadamente 1200 mujeres de 25 o mas años por esta causa, 4 veces mas que el número de muertes por HIV en la misma población. Representa la primer causa de muerte por cáncer entre los 25 a 40 años y las tasas de mortalidad son 5 veces mayores en la provincias del Noroeste respecto de las centrales. ${ }^{7}$ La tasa de mortalidad para el mismo año fue de 11.5 por 100.000 .

Para el mismo periodo y grupo etario, en EE.UU se registraron aproximadamente 4600 muertes y la tasa de mortalidad fue del 3.2 por 100.000. Es decir que mientras la frecuencia de nacimientos en mujeres con mas de 5 hijos es el doble respecto de EE.UU ( $10 \%$ vs $5 \%$ ), las tasas de mortalidad se cuadriplican. Si bien la disminución de la multiparidad en las poblaciones podría explicar en parte la disminución en el tiempo de las tasas de mortalidad por cáncer de cuello, ambos eventos están estrechamente asociados al acceso de las mujeres en edad fértil al sistema de salud. De hecho, los países con mayores tasas de incidencia de carcinoma de cuello tienen menor cantidad de médicos per capita, menor tasa de inmunizaciones, mayores frecuencias de infección por HIV y menor expectativa de vida ?

Conclusiones del comentador: Según este estudio, el incremento de la paridad aumenta el riesgo de cáncer escamoso de cuello, entre mujeres HPV positivas. Debe tenerse en cuenta que en poblaciones subdesarrolladas, un mayor acceso al sistema de salud pudiera ser el real efecto oculto en estos dos eventos.

\section{*Ver glosario}

\section{Dra. M. Paula Cacace; Dr. Hugo Krupitzki [ CEMIC ]}

\section{Referencias}

- Walboomers JMM, Jacobs MV, Manos MM, et al. Human papillomavirus is a necessary cause of invasive cervical cancer worldwide. J Pathol 1999; 189: 12-19.

2-Woodman CBJ, Collins S, Winter H, et al. Natural history of cervical human papillomavirus infection in young women: a longitudinal cohort study. Lancet 2001; 357: 1831-36.

- Schiffman MH, Brinton LA. The epidemiology of cervical carcinogenesis. Cancer 1995; 76: 1888-901.

- Brinton LA, Reeves WC, Brenes MM, et al. Parity as a risk factor for cervical cancer. Am J Epidemiol 1989; 130: 486-96.

- Parazzini F, Chatenoud L, La Vecchia C, Negri E, Franceschi S, Bolis G. Determinants of risk of invasive cervical cancer in young women. Br J Cancer 1998; 77 : 838-41.

Drain PK, Holmes KK, Hughes JP, Koutsky LA. Determinants of cervical cancer rates in developing countries. Int J Cancer. 2002 Jul 10;1.00(2):199-205.

7 -Dirección de Estadísticas e Información de Salud. Ministerio de Salud y Acción Social . República Argentina 2001 